\title{
Mass-Marking of Ayu Eggs and Larvae by Tetracycline-Tagging of Otoliths
}

\author{
Katsumi TsuKamoto*
}

(Accepted November 10, 1984)

\begin{abstract}
The object of this study is to develop a method of mass-marking the egg and larval stages of fish in order to carry out field surveys of the early life history and population dynamics of the fish. In this method the eggs or newly hatched larvae are immersed in tetracycline hydrochloride (TC) solution and marked-fish or fish from treated eggs are detected by the presence of a fluorescent mark on otoliths under UV light.

To determine the optimum TC concentration and treatment time for marking the eggs and larvae of the ayu Plecoglossus altivelis, a diadromous fish, various combinations of TC concentration and treatment time ( $40-44$ lots) were tested. As a result, $200-300 \mathrm{mg} / \mathrm{l}$ for $24-48 \mathrm{~h}$ was found to be appropriate for eggs and $200-300 \mathrm{mg} / \mathrm{ml}$ for $3-24 \mathrm{~h}$ for the larvae. Mark retention and the effect of TC treatment on survival and growth were examined by rearing marked larvae in $500 l$ plastic tanks for more than 5 months. The mark was easily descernible (100\%) until 105 days after hatching without any special preparation for detection. Even 164 days after hatching the percentage of retention was $100 \%$ after grinding or etching in weak acid, compared with $83 \%$ before such treatment. The treatment had no effect on the survival and growth of the ayu. These results strongly suggest that this method can be applied to field surveys on the ayu during early life stage in the sea.
\end{abstract}

Mark-recapture methods are an effective technique for studies on migration, population size, growth rate and behavior of fish. Although various sophisticated techniques have been developed for field studies and aquaria experiments, none is fullproof. An investigator should select a method which complies as far as possible with the requirements of his experiment, in consideration of its objectives, duration, detection method, type of fish (i.e. species, size, stage of life cycle) and so on. ${ }^{1)}$ The early life stages seem to hold the key to understanding fluctuations in fish population and fisheries biologists have long sought an effective means of marking fish eggs and recently hatched larval fish in a manner that would not alter the life functions or mortality of marked fish from those of unmarked fish. If a suitable marking method is available at this early life stage, it would be possible to determine the various population parameters such as density, mortality rate, exploitation rate, and recruitment rate, as well as age, growth and migration.

Vital staining, either by immersion or incorporation of a dye into food, is one of the few methods available for marking very small fish. ARNOLD ${ }^{2)}$ in a review of fish marking with dyes concludes that immersion staining is of value only for shortterm experiments. SAKURAI et al..$^{32}$ reported that the glass eel Anguilla japonica marked with a fluorescent red dye could be detected for 1-2 months after marking and TzENG ${ }^{\text {(2) }}$ demonstrated the application of this method to a field survey of elvers for c.a. 1 month. BaGENAL ${ }^{5)}$ fed maturing female brown trout Salmo trutta with pelleted food mixed dry with powdered Sudan Black. The resulting eggs were darkly stained and the color remained in the fry for 6 weeks after they started to feed themselves. The use of fluorescent materials (e.g. tetracycline or oxytetracycline) as in vivo bone-tissue marker is now popular not only in marking experiments ${ }^{6,7)}$ but also as a time mark in estimates of growth of hard tissue. ${ }^{8,8)}$ TroJNAR ${ }^{10)}$ fed tetracycline hydrochloride to rainbow trout fry and found that although $100 \%$ success in initial marking was not achieved, successfully-marked fish were all recognizable one year later. CAMPANA and NerLsON ${ }^{\theta)}$ suggested that the otoliths of the starry flounder Platichthys stellatus can be marked by immersion in a tetracycline-saline solution. HETTLER ${ }^{11)}$ in his recent work, demonstrated that otoliths of spot (SL, 13-16 mm) Leiostomus xanthurus and pinfish (SL, 12-15 mm) Lagodon

* Ocean Research Institute, University of Tokyo, Minamidai, Nakano, Tokyo 164, Japan. (塚本勝巳: 東京大学海洋研究所) 
rhomboides could be marked by immersion in oxytetracycline solution. In addition to the above techniques, trace element and nonradioactive isotopes appear to be effective for marking fish eggs and larvae..$^{12-14)}$ By X-ray-existed optical luminescence spectroscopy, MUNCY and D'SiLVA ${ }^{18)}$ detected $\mathrm{Tb}$ (terbium) in 3-week old walleye fry hatched from Tb-labeled eggs immersed in terbium dicitrate solution.

All of the above methods, however, have some disadvantages in regard to retention time, success of initial marking and/or involve trouble and cost in detection of marked fish and are not very suitable for mark-recapture studies in the wild. The object of this study is to develop a massmarking method for fish eggs and newly hatched larvae. In this paper, I describe mass-marking of eggs and larvae of the ayu Plecoglossus altivelis by tetracycline-tagging of otoliths and discuss the possibility of application of this method to field surveys of this species.

\section{Materials and Methods}

The ayu used in this study is a commercially important species not only for fish culture but also for game fishing. Artificial fertilization and rearing of the species are carried out extensively in Japan. The ayu is categorized as a diadromous fish and is famous for its one-year life span and territorial behavior. ${ }^{18)}$ It feeds on adhesive algae on rocks. The fish matures in the river and lays adhesive eggs among gravel in the middle or lower reaches of the river in the fall. Eggs hatch out 10-14 days after fertilization at water temperature of $15-20^{\circ} \mathrm{C}$. Newly hatched larvae are soon carried out to sea and the fish spend c.a. 6 months in the sea before beginning upstream migration in the spring.

This study consists of three experiments. In Experiment 1, the optimum concentration of tetracycline (TC) and treatment time are examined. Experiment 2 deals with the retention time of the fluorescent mark on otoliths, while Experiment 3 is concerned with the effects of TC treatment on hatching, survival and growth of larvae. Materials and marking procedures in each experiment are summarized in Table 1. All materials were obtained through artificial fertilization following standard ayu hatchery procedures. Experiments were carried out at Gifu-ken Gyobyo Center (Gifu Pref. Ayu Hatchery), Mino City, Gifu Pref.

\section{Experiment 1: Optimum TC Concentration and Treatment Time}

This experiment is further divided into two tests (Table 1). In the egg test, 30 eggs at the eyed stage attached to a slide glass were used for each lot. Forty-four lots were subjected to various combinations of TC concentration $(0-2000 \mathrm{mg} / l)$ and treatment time $(1.5-48 \mathrm{~h})$ in fresh water in $100 \mathrm{~m} /$ covered beakers (see Fig. 2). In the larva test, 50 newly hatched larvae were used for each lot. In this case, forty lots were exposed to various combinations of TC concentration $(0-1000 \mathrm{mg} / \mathrm{l})$ and treatment time $(1.5-24 \mathrm{~h})$ in $200 \mathrm{ml}$ covered beakers (see Fig. 3). All lots in both tests were incubated in a water bath at $20^{\circ} \mathrm{C}$ under light conditions of $0-400 \mathrm{~lx}$. Fish were not fed

Table 1. Materials and processes used in the three experiments

\begin{tabular}{|c|c|c|c|c|c|c|c|c|c|}
\hline \multirow{2}{*}{ Exp. } & \multicolumn{2}{|c|}{ Initial materials } & \multicolumn{3}{|c|}{ Marking treatment } & \multirow{2}{*}{$\begin{array}{l}\text { No. of } \\
\text { lot }\end{array}$} & \multirow{2}{*}{ Container } & \multirow{2}{*}{$\begin{array}{c}\text { Test } \\
\text { period } \\
\text { (day) }\end{array}$} & \multirow{2}{*}{$\begin{array}{c}\text { Rearing } \\
\text { temp. } \\
\left({ }^{\circ} \mathrm{C}\right)\end{array}$} \\
\hline & life stage & No./lot & $\begin{array}{c}\mathrm{TC} \text { conc. } \\
(\mathrm{mg} / I)\end{array}$ & $\underset{(h)}{\text { time }}$ & $\begin{array}{l}\text { WT } \\
\left({ }^{\circ} \mathrm{C}\right)\end{array}$ & & & & \\
\hline $\begin{array}{l}\text { Exp. } 1 \\
\text { egg test }\end{array}$ & $\begin{array}{l}\text { eggs } 7-8 \\
\text { days after } \\
\text { fertilization }\end{array}$ & 30 & $0-2000$ & $1.5-48$ & 20 & 44 & $\begin{array}{l}100 \mathrm{ml} \\
\text { covered } \\
\text { beaker }\end{array}$ & 10 & 20 \\
\hline larva test & $\begin{array}{l}\text { larvae } 0-4 \\
\text { days after } \\
\text { hatching }\end{array}$ & 50 & $0-1000$ & $1.5-24$ & 20 & 40 & $\begin{array}{l}200 \mathrm{ml} \\
\text { covered } \\
\text { beaker }\end{array}$ & 3 & 20 \\
\hline Exp. 2 & $\begin{array}{l}\text { larvae } 2 \\
\text { days after } \\
\text { hatching }\end{array}$ & 3000 & 100 & 7 & 20 & 1 & $\begin{array}{l}500 l \\
\text { plastic } \\
\text { tank }(\phi 100 \mathrm{~cm})\end{array}$ & 164 & $12-21$ \\
\hline $\begin{array}{l}\text { Exp. } 3 \\
\text { treated } \\
\text { control }\end{array}$ & $\begin{array}{l}\text { larvae } 2 \\
\text { days after } \\
\text { hatching }\end{array}$ & $6000^{*}$ & $\left\{\begin{array}{r}100 \\
0\end{array}\right.$ & 7 & $\left.\begin{array}{l}20 \\
20\end{array}\right\}$ & 1 & $\begin{array}{l}500 l \\
\text { plastic } \\
\text { tank }(\phi 100 \mathrm{~cm})\end{array}$ & 164 & $12-21$ \\
\hline
\end{tabular}

\footnotetext{
- 3000 treated fish and 3000 control fish kept together in a tank.
} 

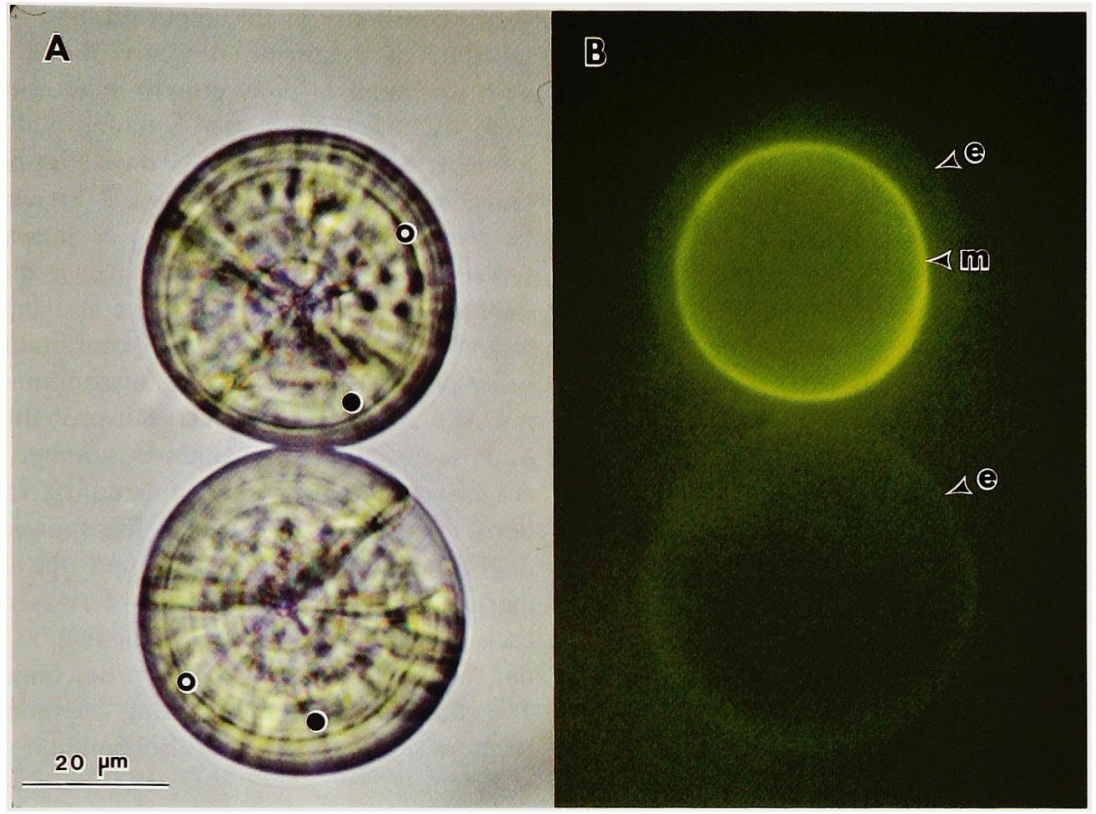

Fig. 1. Comparison of sagitta otoliths between marked and unmarked fish 10 days after hatching. Photographs $\mathbf{A}$ and $\mathbf{B}$ are of the same samples without any changes in magnification, framing or focus, but with different lighting conditions, i.e. normal white light and UV light, respectively. The upper otolith in each photograph was extracted from TC treated fish $(100 \mathrm{mg} / /$ for $7 \mathrm{~h}, 2$ days after hatching) and the lower, from control fish. $\mathbf{m}$ : fluorescent mark; e: edge of otolith. Open circle $(O)$ : the discontinuities corresponding to the time of the marking operation. Solid circle $(\bullet)$ : the ring which seems to correspond to the day of hatching.

during the experiment. Ayu larvae survived at least one week after hatching without food $^{17), *}$ and the results of this experiment do not seem to have affected by the feeding conditions.

Hatching success was observed 10 days after the start of treatment in the egg test. As for the larva test, survival rates were determined 3 days after the beginning of treatment. Five individuals were sampled out of the surviving fish in each lot. A pair of sagitta otoliths were extracted from each fish and mounted in euparal on a slide glass. The fluorescent mark on the otoliths was examined with a UV light microscope. Clearness of marking was estimated individually (not for each saggita) and ranked "clear", "faint" or "no", each rank being given 2,1 and 0 points, respectively. If the total number of points of 5 individuals in a lot was more than 6 , the lot was considered to be successfully marked.

\section{Experiment 2: Mark Retention Time}

Larvae 2 days after hatching were immersed in
$100 \mathrm{mg} / / \mathrm{TC}$ solution of fresh water for $7 \mathrm{~h}$ at $20^{\circ} \mathrm{C}$. About 3000 marked larvae were kept in a $500 /$ plastic tank and reared with rotifer and commercial food for more than 5 months from October 1983 till March 1984. The water temperature ranged from 12 to $21^{\circ} \mathrm{C}$. The rearing tank was placed indoors near a window. Since the ceiling and the wall of the rearing house were semitransparent, the fish were considered to be reared under natural photoperiod conditions.

Upon occasion, c.a. 15 times during the experiment, 50-100 fish were sampled from the rearing tank. A pair of otoliths was removed from each individual and mounted in the same manner as in the Experiment 1. The percentage of detectable fish, whose fluorescent mark on the otoliths was discernible, was determined for each sampling time. In the standard method of detection, no pre-treatment of the otolith was required. However, for otoliths the fluorescent mark of which was undetectable, the convex side of the otolith was ground a little on a whetstone or etched in weak

* Tsukamoto et al., unpublished data. 
formic acid.

Experiment 3: Effect of TC Treatment on Survival and Growth

About 3000 marked larvae from the same lot used in Experiment 2 and the same number of control fish, which were immersed in fresh water containing no $\mathrm{TC}$ for $7 \mathrm{~h}$, were kept together in one rearing tank. They were reared in the same manner as in Experiment 2 and random sampling of 50-100 fish was similarly carried out on occasion. A pair of otoliths was extracted from each fish and examined by UV light microscopy to determine whether it was a marked or unmarked fish. The numbers of marked and unmarked fish were determined for each sampling time and the survival of both groups were compared based on the fluctuation of the percentage of marked fish in the rearing tank. At the same time, the changes in body length of both groups were monitored.

\section{Results}

An example of a marked otolith and an unmarked one is presented in Fig. 1. The marked otolith in the figure was sampled from the rearing tank of Experiment 2. Fig. 1-A is a photograph taken under normal lighting and Fig. 1-B under UV light. The upper otolith in Fig. 1-A which was marked in $100 \mathrm{mg} / / \mathrm{TC}$ solution for $7 \mathrm{~h}$ is clearly discernible in Fig. 1-B as a gleaming yellow ring standing out against a dark green background, while the lower one which is a control disappears in the UV light photo. Thus, marked fish can easily be distinguished from unmarked ones. If Fig. 1-B is observed closely, one can find a faint greenish yellow ring just at the edge of the control otolith (lower) and similarly outside the fluorescent mark of the treated one (upper). These faint rings seem to be caused by birefringence at the edge of otolith or autofluorescence of the margin.

We have found that the ayu exhibits exact daily growth increaments and age determination in this species is possible throughout its life history.* This was determined by time marking through tetracycline injection and by comparing the actual age of reared fish from eggs with the number of increments. There wert clear discontinuities 4-5 rings inside from the edges of both otoliths in Fig. 1-A. It was apparent that these discontinuities corresponded to the time of the marking operation since the diameter of the fluorescent mark in Fig. 1-B was exactly the same as that of the discontinuity in the upper otolith. The time schedule of treatment, however, did not accord with the count of daily growth increments. Fish were treated 2 days after hatching and sampled a further 8 days after that ( 10 days after hatching). Outside of these discontinuities, 7-8 rings should be present, but in fact, only $4-5$ rings were observed. The formation of daily growth increments might have ceased for $2-4$ days and this period might corresponded to the discontinuities. Another point to note is that the discontinuities were not caused by the drug (TC) but probably by the other factors such as changes in salinity, nutritive conditions and the stress of handling etc., since both TC marked and control fish showed similar discontinuities. If we could find the hatching marks, they should be located 2 rings inside of each discontinuity. However, neither TC marked nor control otolith had clear hatching marks. The stress following the marking operation might be more severe for the otolith formation than that at hatching.

\section{Experiment 1: Optimum TC Concentration and Treatment Time}

Figs. 2 and 3 show the range of TC concentration and treatment time that can be used for marking eggs and larvae, respectively. The upper line at the edge of the shaded area shows the lethal limit and the lower line the minimum treatment for successful marking. The effect of treatment time seems to be greater in eggs than in larvae, and the available range for marking is wider in larvae than in eggs. The time of day when treatment is carried out might affect marking success. TANAKA et $a t^{19}{ }^{19}$ found a daily rhythm in otolith growth responding to laboratory photoperiod in Tilapia nilotica. Although a daily rhythm has not been established in ayu, yet, it seems preferable that the duration of treatment is kept sufficiently long to avoid the possible effects of such a rhythm. Water temperature also probably affects marking success. However, no data at any temperature other than $20^{\circ} \mathrm{C}$ was obtained. In conclusion, immersion in 200-300 $\mathrm{mg} / /$ for $24-48 \mathrm{~h}$ is recommended for marking eggs and in $200-300 \mathrm{mg} / /$ for $3-24 \mathrm{~h}$ for larvae.

\section{Experiment 2: Mark Retention Time}

Figs. 4, 5 and 6 are pairs of photographs taken under normal and UV lighting at 61, 105 and 164 days after hatching, respectively. Fluorescent

* Tsukamoto and Kajihara, unpublished data. 


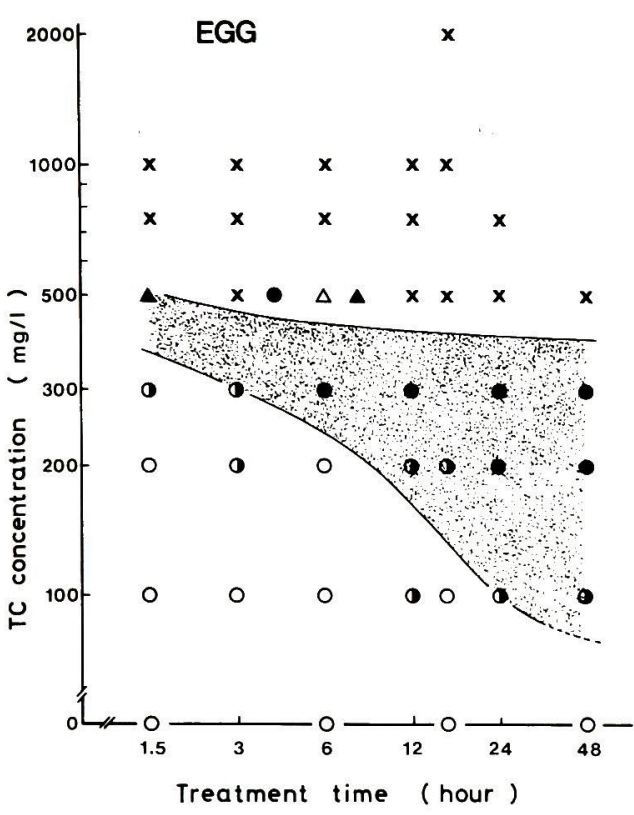

Fig. 2. Optimum range of $\mathrm{TC}$ concentration and treatment time for marking ayu eggs. Circle $(0)$ : hatching rate $\geqq 90 \%$; triangle $(\triangle)$ : $0-90 \%$; cross $(x):=0 \%$. Shaded symbol: marked clearly; open symbol: marked unsuccessfully; semi-shaded symbol: marked with intermediate success.

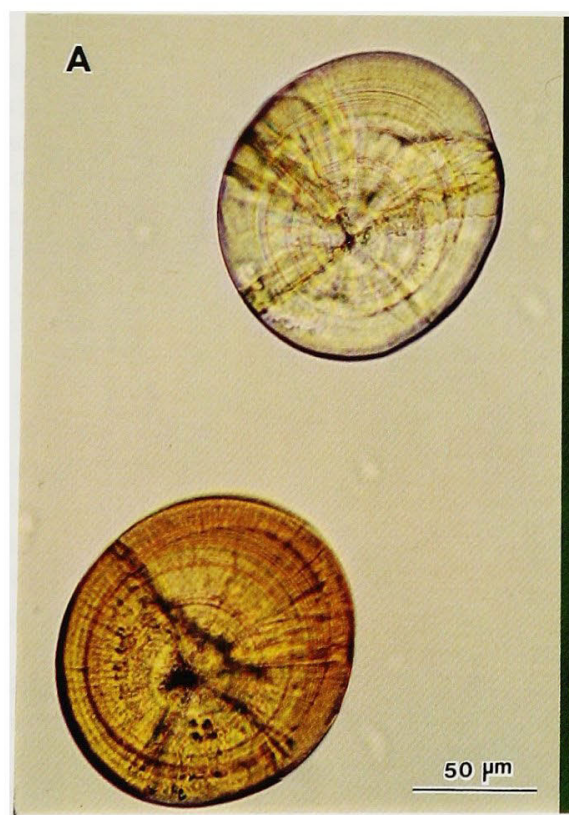

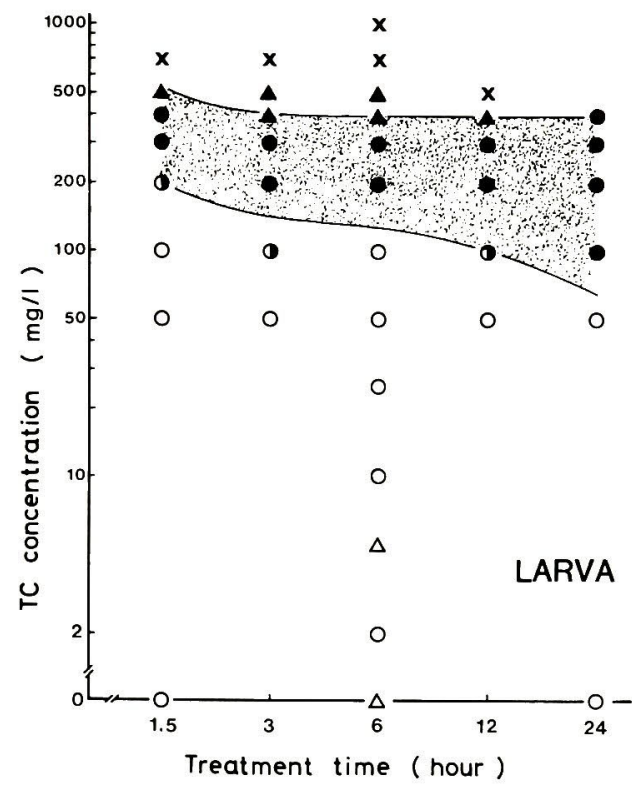

Fig. 3. Optimum range of TC concentration and treatment time for marking ayu larvae. Circle (1): survival rate $\geqq 80 \%$; triangle $(\triangle)$ : $0-80 \%$ : cross $(\times)$ : $=0 \%$. Shaded symbol: marked clearly; open symbol: marked unsuccessfully; semi-shaded symbol: marked with intermediate success.

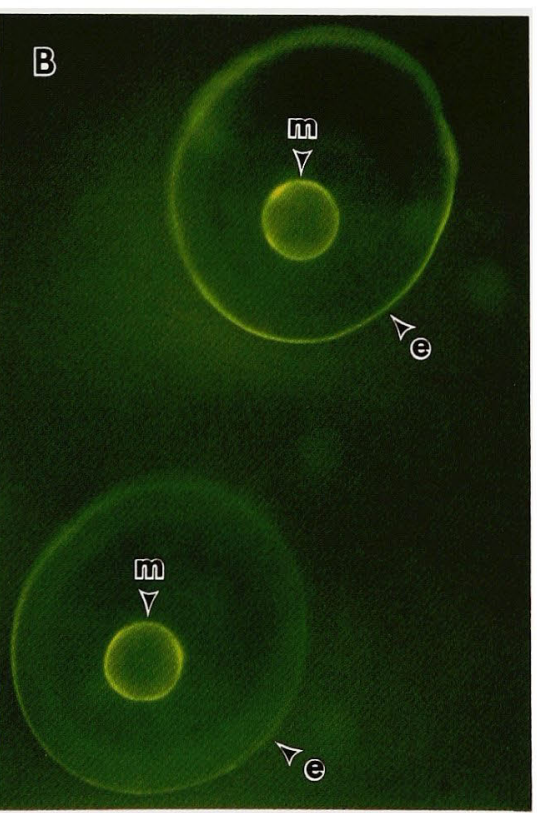

Fig. 4. Photographs of otoliths of 61-day old fish treated for $7 \mathrm{~h}$ in $100 \mathrm{mg} / \mathrm{l} \mathrm{TC}$ solution 2 days after hatching. A: normal white lighting; B: UV lighting. m: fluorescent mark; e: edge of otolith. 


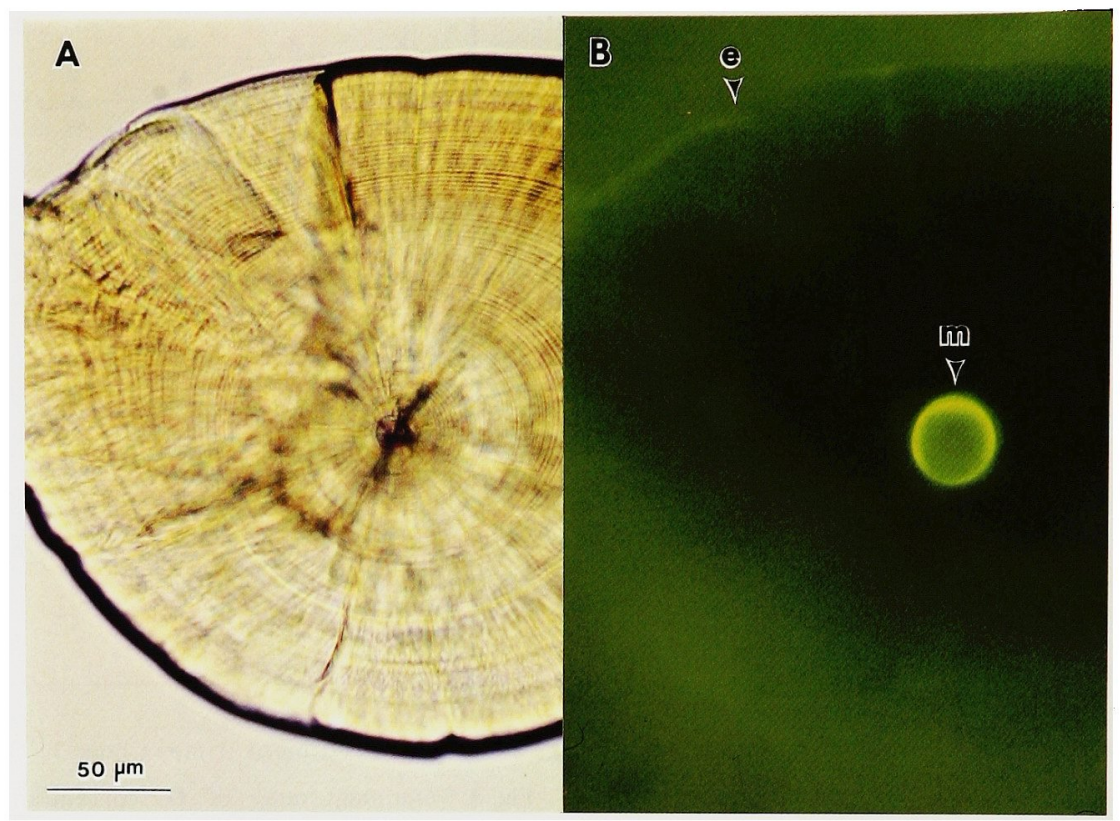

Fig. 5. Photographs of otoliths of 105-day old fish sampled from the same lot as in Fig. 4. A: normal white lighting; B: UV lighting. m: fluorescent mark; e: edge of otolith.

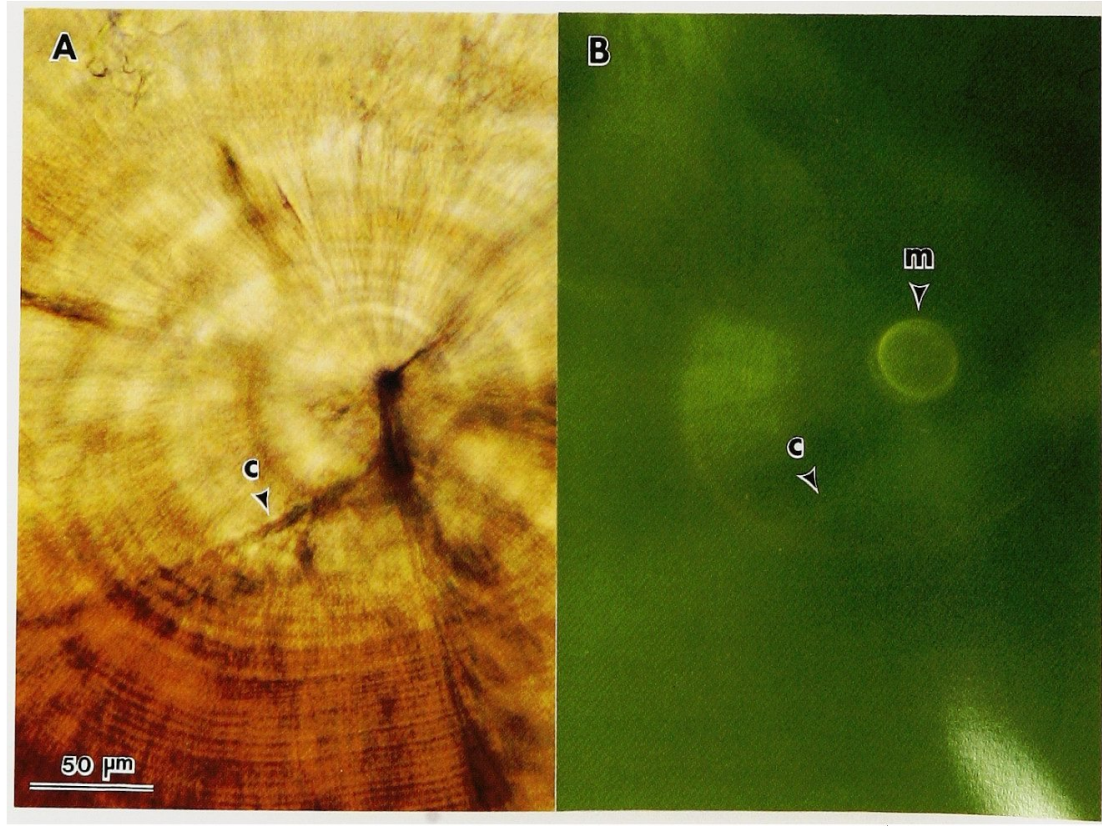

Fig. 6. Photographs of otoliths of 164-day old fish sampled from the same lot as in Fig. $4 . \mathrm{A}$ : white lighting; B: UV lighting. $\mathrm{m}$ : fluorescent mark; $\mathbf{c}$ : cracks in otolith. The fluor mark at 164 days was not so clear as those at 61 and 105 days because of thickening and $c$ tion of the otolith during growth. 
Table 2. Retention time of the mark on otoliths of fish treated for 7 hours in $100 \mathrm{mg} / l \mathrm{TC}$ solution 2 days after hatching

\begin{tabular}{|c|c|c|c|c|}
\hline Sampling date & Days after hatching & $\begin{array}{l}\text { Fish with mark/ } \\
\text { Examined fish }\end{array}$ & $\begin{array}{l}\text { Percentage of } \\
\text { fish with mark }\end{array}$ & $\mathrm{SL}^{* 1}(\mathrm{~mm})$ \\
\hline $10 / 24, ' 83$ & 12 & $60 / 60$ & 100 & $11 \pm 0.6$ \\
\hline $12 / 12,{ }^{2} 83$ & 61 & $30 / 30$ & 100 & $15 \pm 1.5$ \\
\hline $1 / 25, ' 84$ & 105 & $30 / 30$ & 100 & $27 \pm 1.8$ \\
\hline $3 / 24, ' 84$ & 164 & $\begin{array}{l}25 / 30 \\
(30 / 30)^{* 2}\end{array}$ & $\begin{array}{c}83 \\
(100)^{* 2}\end{array}$ & $49 \pm 4.5$ \\
\hline
\end{tabular}

Table 3. Effect of TC marking on survival and growth in the ayu

\begin{tabular}{cccccc}
\hline Sampling date & $\begin{array}{c}\text { Days after } \\
\text { hatching }\end{array}$ & $\begin{array}{c}\text { Marked fish/ } \\
\text { Examined fish }\end{array}$ & $\begin{array}{c}\text { Percentage of } \\
\text { marked fish }\end{array}$ & \multicolumn{2}{c}{ SL* (mm) } \\
\hline $10 / 24,{ }^{\prime} 83$ & 12 & $13 / 30$ & 43 & $11 \pm 1.0$ & $11 \pm 0.5$ \\
$12 / 12, ' 83$ & 61 & $18 / 30$ & 60 & $18 \pm 1.0$ & $18 \pm 0.8$ \\
$1 / 25, ' 84$ & 105 & $15 / 30$ & 50 & $26 \pm 3.4$ & $27 \pm 2.0$ \\
$3 / 24,{ }^{\prime} 84$ & 164 & $12 / 30$ & 40 & $52 \pm 3.9$ & $53 \pm 4.4$ \\
\hline
\end{tabular}

- mean \pm S.D.

marks on otoliths are clearly discernible until 105 days after hatching (see Figs. 4 and 5). At 164 days after hatching, the mark became faint. The percentages of marked fish for each sampling time are shown in Table 2. Twelve days after hatching, all 60 fish examined had clear marks. This indicates $100 \%$ initial success in marking. Until 105 days, $100 \%$ detection was still possible. At 164 days, the percentage decreased to $83 \%$, perhaps because of thickening and coloration following otolith growth. Since otoliths grow by accumulating calcium layer upon layer, the tetracycline labeled part of the otolith must be near the nuclei of the otolith. When undetectable otoliths were ground or etched in weak acid and observed again, the marks were clearly detected. Thus, the mark was retained for at least five and a half months. Moreover, the results of Experiment 1 indicate that the treatment of Experiment 2 was the absolute minimum required for marking success and, thus, more adequate treatment would undoubtedly raise the percentage of detection at 164 days.

\section{Experiment 3: Effect of TC Treatment on Survival and Growth}

The effects of marking treatment on survival and growth are shown in Table 3. At the beginning of this experiment, marked fish and unmarked control fish were present in roughly equal numbers in the tank. From the results in Experiment 2, the fish without detectable mark could be regarded as untreated control fish at the beginning of the experiment and those with marks as marked fish. The percentages of marked fish show an almost constant value of about $50 \%$ for 164 days though a small fluctuation of less than $10 \%$ is observed. The fluctuation may merely result from the small number of fish examined. However, the following explanation may also be possible. The lots treated in 0 and $5 \mathrm{mg} / \mathrm{l}$ for $6 \mathrm{~h}$ in Fig. 3 showed lower survival rates than those treated at a higher TC concentration $(10-300 \mathrm{mg} / l)$. This suggests that TC may favor survival of the ayu larvae, and this may account for the increase in the percentage of marked fish from 43 to $60 \%$ between 12 and 61 days. Furthermore, since no special preparation of otolith, such as grinding or etching, was adopted for detection in this experiment, the decrease at 164 days may be explained by the small decrease in the percentage of detectable fish at 164 days in Experiment 2 when the standard procedure was followed. Whether or not this is correct, it can be concluded that TC treatment has no serious effect on the survival of the ayu.

Body lengths of marked and unmarked fish showed almost the same values throughout the experiment. It is thus apparent that growth is not affected by the treatment.

\section{Discussion}

The merits and demerits of the marking method 
described here can be summarized as follows. Its merits are: (1) it can be used for eggs and newly hatched larval stages; (2) rapid mass-marking with $100 \%$ initial success can be achieved; (3) the retention time is comparatively long; (4) it has no effect on fish's growth or mortality; (5) in laboratory experiments, different groups of fish marked at the egg stage can be raised together under the same rearing conditions. On the other hand, the biggest disadvantage in this method is the troublesome process for detection, namely, the extraction of otoliths and detection by incident UV light microscopy. I am now trying to establish an easy and rapid method for mass-extraction of otoliths and fast preparation for detection. Another dermerit is that only a few combinations of different colored marks seem to be possible in an experiment because few fluorescent materials are available at present that can be applied to otolith marking. Calcein and alizarin complexon have low toxity and present clear fluorescence of palegreen and red, respectively. $\left.{ }^{1 \theta}\right)$ These chemicals are now undergoing trial. Despite these dermerits, this method of otolith marking still seems to have many advantages over previous marking methods. The principle of the marking method described here is essentially the same as that discribed by HeTtLER who used $12-16 \mathrm{~mm}$ fish. ${ }^{11}$ He, however, tried to use the fluorescent mark on otolith as a time mark, not for mark-recapture studies in the field but for the validation of daily growth increment. $\mathrm{He}$ also suggested at the same time that the yellow fluorescence in heads and fins, especially caudal fins* might be used for mark-recapture studies if the longevity of the external fluorescence is known. ICHII and MUGrYA ${ }^{20)}$ proved in ${ }^{45} \mathrm{Ca}$-prelabeled goldfish Carassius auratus that the calcium turnover rate was highest in scales, next came bones and last otoliths and that, once deposited, calcium on otoliths was mobilized little if at all. From this point of view, therefore, otoliths are the ideal calcium-containing tissue for tetracycline marking. Although special preparation (i.e. grinding or etching) must be adopted for otoliths older than 5 months, the retention time of the tetracycline mark on otoliths is considered to be sufficient for field studies of the ayu whose life span is only one year. Tetracycline-tagging also seems to be suitable for other diadromous species such as Salanx microdon and Leucopsarion petersi which have thin flat saggitae and short life spans. Moreover, tag loss does not occur because otoliths are in effect "biological internal tags". As LAIRD and STOTT" pointed out, however, it is known that sunlight can deactivate tetracycline. However, once pigmentation around the fish head is completed at the juvenile stage, tetracycline combined with the calcium of otolith is probably protected from natural UV rays by the pigmentation. Mark retention is now being examined in eggs and larvae stocked in the wild and the outdoor rearing tanks.

\section{Acknowledgements}

I wish to express my thanks to $\mathrm{K}$. UCHDA for his co-operation in rearing and sampling fish. The experiments in this study were conducted at Gifu-ken Gyobyo Center. I am also indebted to the staff of the Center for their co-operation in rearing fish and in making facilities available for carrying out the experiments. The eggs used in this study were generously supplied by Gunma Pref. Fisheries Experimental Station. Thanks are also due to Prof. T. Kajihara of Ocean Research Institute, University of Tokyo and Dr. R. IsHIDA of Tokai Regional Fisheries Research Laboratory for their active interest and encouragement throughout the study.

\section{References}

1) L. M. LAIRD and B. StotT: in "Methods for Assessment of Fish Production in Fresh Waters" (ed. by T. BAGENAI), IBP Handbook No. 3, Blackwell Scientific Publications, Oxford, 1978, pp. 84-100.

2) D. E. ARnold: Tech. Pap. Fish. Wildl. Serv. U.S., 10, pp. 44 (1966).

3) N. Sakurai, M. IKemori, and S. Arasari: Bull. Coll. Agr. \& Vet. Med., Nihon Univ., 36, 285-289 (1979).

4) W. N. TzEng: Bull. Japan. Soc. Fish, Oceanogr., 45, 10-19 (1984).

5) T. B. Bagenal: Nature, 214, 113 (1967).

6) D. Weber and G. J. Ridgeway: J. Fish. Res. Bd. Can., 27, 849-865 (1967).

7) W. J. Scromore and D. F. Olson: Progue. Fish. Cult., 31, 213-216 (1969).

8) A. WILD and T.J. ForemaN: Inter-American Tropical Tuna Commission Bull., 17, 509-560 (1980).

9) S. E. Campana and J. D. Neilson: Can. J. Fish. Aqua. Sci., 39, 937-942 (1982).

10) J. R. Trojnar: Progve. Fish. Cult, 35, 52-54 (1973).

11) W. F. Hettler: Trans. Amer. Fish. Soc., 113, 370-373 (1984).

12) P. S. Trefethen and A. J. Novotny: Interna-

* Maybe, he meant fin rays. 
tional Commision for the Northwest Atlantic Fisheries Special Publication, North Atlantic Fish Marking Symp., 64-65 (1963).

13) W. P. MrLler: Mr. Thesis, Univ. Washington, Seattle, Washington, USA, (1963).

14) ANonYmous: International North Pacific Fisheries Commision Annual Report 1972, pp. 55, (1974).

15) R. J. Muncy and A. P. D' Silva: Trans. Amer. Fish. Soc., 110, 300-305 (1981).

16) H. KaWANABE: Symposium on salmon and trout in streams, McMillan Lect. Fish., Univ. Brit.
Columb., Canada, 243-259, (1969).

17) T. Iro, T. IwaI, and T. FuruIchI: Kiso-sansen Kako-shigen Chosa Hokokusho (KST Report), 5, 585-616 (1968).

18) K. Tanaka, Y. Mugiya, and J. Yamada: Fish. Bull., U.S., 79, 459-466 (1981).

19) M. Takahashi, T. Kawaguchi, S. Nakajima, $Y$. Asano, and M. TAtsuguchi: Odontology, 67, 53-66 (1979).

20) T. Ichil and Y. MugrYa: Bull. Japan. Soc. Sci. Fish., 49, 1039-1044 (1983). 